convulsive episode. One child was found with unilateral retinal hemorrhages following a simple febrile convulsion. No other reason for the hemorrhage was uncovered. It was concluded that retinal hemorrhages following a convulsive episode are rare and should trigger a search for other causes, including child abuse. (Mei-Zahav $\mathrm{M}$ et al. Convulsions and retinal hemorrhages: should we look further? Arch Dis Child 2002;86(5):334-335).

In 2 cases of infants with hyponatremic seizures examined at Franklin Square Hospital, Baltimore, MD, retinal hemorrhages were an unexpected finding. Long bone fractures and subdural hematoma were associated in one case of shaken baby syndrome, and cerebral edema in case 2 was presumed to be the result of child abuse. Children with hyponatremic seizures are often neglected and are at risk of other forms of child abuse. (Krugman SD, et al. Pediatr Emerg Care 2000;16(6):432-434).

\title{
BENIGN ROLANDIC EPILEPSY AND LEARNING DISABILITIES
}

Neuropsychological impairments in 35 children with rolandic epilepsy, and the relationship to electroencephalographic findings, were studied at Ege University, Izmir, Turkey. Patients showed significant impairments of visuomotor and reading ability and attention to verbal stimuli compared to controls. Reading disability persisted on follow-up, despite resolution of EEG seizure discharges and remission of seizures. Cognitive disorders were not related to antiepileptic drugs, and occurred in untreated subjects. Patients should be followed to identify learning problems. (Ay Y, Gokben S, Serdaroglu G, et al. Neuropsychological impairment in children with rolandic epilepsy. Pediatr Neurol Nov 2009;41:359-363). (Respond: Dr Ay, Department of Pediatrics, Faculty of Medicine, Ege University, 35100 Izmir, Turkey. E-mail: dryilmazay@yahoo.com).

COMMENT. Contrary to the so-called benign nature of BECTS, the disorder is sometimes associated with learning disabilities, especially reading problems, while a normal IQ is preserved.

Impairment in attention in rolandic epilepsy evaluated in 14 studies published between 1990 and 2006, in a study at Columbia University, NY, found at follow-up when the EEG had normalized, that attention problems had almost completely resolved. (Kavros PM et al. Epilepsia 2008;49:1570-1580; Ped Neur Briefs Oct 2008;22(10):77-78). Rolandic spikes may aggravate the course of ADHD and predispose to increased impulsivity (Holtmann M et al. Brain Dev 2006;28:633-640).

\section{ATTENTION DEFICIT DISORDERS}

\section{RATINGS OF ATTENTION PROBLEMS IN ADHD: A CONTINUUM}

To determine whether ADHD should be classified in three distinct DSM-IV diagnostic subtypes or a continuum of attention problems, maternal ratings of attention on the Child Behavior Check List (CBCL), in Durch boys at age 7, 10, and 12 years, were fitted to class models, assuming either subtype or severity differences. The fit of the models to the data is compared, to determine which model is appropriate. Researchers at the Universities of Notre Dame, IN; Vermont; Utrecht; and Amsterdam conducted the study. At all three ages 